\title{
Disseminated Tuberculosis - A Case Study
}

\author{
Aye $\mathrm{M}^{1 *}$, Cabot $\mathrm{JSF}^{2}$, Baba $\mathrm{S}^{3}$, Thanabalan $\mathrm{MC}^{4}$ and Chung $\mathrm{SF}^{2}$ \\ ${ }^{1}$ Department of Medicin, Melaka Manipal Medical College, Malaysia \\ ${ }^{2}$ Department of Medicine, UniKL Royal College of Medicine, Perak, Malaysia \\ ${ }^{3}$ Department of Radiology, Ipoh General Hospital, Perak, Malaysia \\ ${ }^{4}$ Medical Officer, Hospital Sungai Siput, Malaysia
}

"Corresponding author: Aye M, Department of Medicine, Melaka Manipal Medical College, Malaysia, Tel: 243 2635 2637; E-mail: mraaye@hotmail.com

Received date: April 07, 2014, Accepted date: April 23, 2014, Published date: May 02, 2014

Copyright: @ 2014 Aye M, et al. This is an open-access article distributed under the terms of the Creative Commons Attribution License, which permits unrestricted use, distribution, and reproduction in any medium, provided the original author and source are credited.

\begin{abstract}
Disseminated Tuberculosis (TB) is a potentially lethal disease if not diagnosed and treated early.It still remains if the presentation is non-specific, unusual and the relevant facts are overlooked. However, a high index of clinical suspicion and early diagnosis and timely institution of anti-tuberculosis treatment is life-saving. Here we did a case study of disseminated tuberculosis with unusual presentation.
\end{abstract}

Keywords: Disseminated tuberculosis; Non-specific; Relevant facts

\section{Introduction}

In 1700, John Jacob Manget1described a form of disseminated tuberculosis. He coined the term military TB (derived from the Latin word miliaritus, meaning related to millet seed) to denote this fatal form of miliary $\mathrm{TB}$ (Disseminated TB) results from a massive lymphohaematogeneous dissemination from a Mycobacterium tuberculosis- laden focus. Miliary TB is often a perplexing disease with diagnosis eludingexperienced clinicians, due to a myriad of clinical presentations and atypical radiologic findings. Hence mortality remains high despite available effective therapy. Disseminated TB has recently been increasingly recognized in adults. This is due to prevalence of immune suppression of acquired immunodeficiency syndrome (AIDS), immunosuppressive therapies for various medical disorders including transplants, and chronic haemodialysis programmes [2]. Amongst immunocompetent adults, miliary TB accounts for less than 2 percent of all $\mathrm{TB}$ cases and up to 20 percent of all extra-pulmonary TB cases [3-9].

We report a case study of Miliary Tuberculosis in an immunocompetent patient where severe granulocytosis and increased alkaline phosphatase were dominating features.

\section{Case in Detail}

A 16-year-old young lady was admitted to district hospital following three weeks of low grade fever and non-productive cough with haemoptysis during last two days. There were no other respiratory or relevant symptoms and physical examination was unremarkable apart from a BCG scar on left arm. Full blood count revealed severe neutrophilicleucocytosis and normocytic anaemia, liver function tests: fivefold high alkaline phosphatase with normal bilirublin level and minimally elevated transaminases, low albumin and albumin to globulin ratio was reverse. Serum ferri urinalysis was normal as were electrolytes. Blood cultures were negative $\mathrm{x} 3$. Sputum stain for acid fast bacilli (AFB) was negative $\mathrm{x}$ 3.Monteux test was negative. Sputum for AFB culture was in progress. Serology for
Hepatitis B antigen, Hepatitis C, HIV and Leptospirosis antibodies were negative. Blood film for malaria parasite was negative. Serum B12 was high. Hepatic ultrasound to rule out liver abscess, suggested "anterior abdominal wall abscess" and a CT scan was ordered but not immediately available (not done at faculty).

Working diagnosis was intra-abdominal abscess with septicaemia. Intravenous (IV) cefuroxime was given for one week then changed to IV ceftriaxone with IV metronidazole added for one week. IV Ciprofloxacin $500 \mathrm{mg}$ BD was then given alone for an additional week and the temperature gradually normalized. However, the patient's neurologic status deteriorated with headaches, obtundation, without nausea or nucheal rigidity, and ultimately generalized tonic-clonic seizures. She was transferred to a secondary level hospital, where her Glasgow Coma Scale was 6/15 (Eye 2, Motor 3, verbal 1). She was transferred out to ICU and anti-TB regime was initiated when CT thorax scan revealed small bilateral pleural effusions and multiple small nodules in the bases of both lungs. Brain CT scan showed hydrocephalus indicating basal meningitis. A PCR for TB bacilli/ Indian ink preparation for Cryptococcus/AFB stain and culture/ biochemistry and cellular study of CSF fluid were requested.

CT scan of abdomen and pelvis showed no focal lesion in the anterior abdominal wall. There was omental caking in the abdomen and pelvis with ill-defined bowel wall. Both ovaries were enlarged with cystic lesions. Part of omental caking at lower anterior abdomen, was abutting the superior wall of urinary bladder, probably accounting for the mass noted on ultrasound. Small nodules suggestive of peritoneal deposits were seen and right sub-diaphragmatic soft tissue collection noted. No hepatic focal lesions were noted and there was a small amount of ascites.

In subsequent weeks, the full blood count normalised except for anaemia, but she developed severe anti-TB drug induced hepatitis and septicaemia due to ventilator associated pneumonia from which she recovered well with appropriate antibiotics and excellent care. Mycobacterium tuberculosis complex was finally identified on sputum culture six weeks after admission to primary hospital. The diagnostic procedure by mini-laprotomy demonstrated purulent and caseous material removed from the peritoneal cavity, adhesions of the small 
Page 2 of 4

intestine. Peritoneal biopsy showed granuloma with central caseation necrosis surrounded by lymphocytes with epitheloidhistiocytes and Langhan's giant cells seen. Zeihl-Neilson stain for AFB was negative and no fungal bodies or malignancy identified.

In follow up 12 months after completing of anti-TB therapy she was neurologically intact, and had regained weight to normal.

\section{Discussion}

Pulmonary tuberculosis was considered in this patient who presented with prolonged fever and cough with haemoptysis despite a normal chest $\mathrm{X}$-ray, negative sputum $\times$ three, and negative Monteux test. However, severe persistent neutrophilicleukocytosis was thought very unusual in cases of pulmonary TB [10]. Some anti-TB effect of fluroquinolones (injection IV Ciprofloxacin $500 \mathrm{mg}$ BD for one week) probably accounted for the defervescence with ciprofloxin. Cerebral function deterioration provoked initiation of anti-TB treatment, (dosage and regime in appendix A) supported by military shadows in the bases of both lungs in CT thorax and CT abdomen dispelled the notion of abdominal wall abscess. Multi organ involvement; lungs, meninges, fivefold high alkaline phosphatase (indicating liver involvement), intestine, spleen and pelvic organs on CT abdomen fulfilled the definition of disseminated tuberculosis.

Combination of lung, liver and pelvic organ was consistent with reports [11] of most common combination with disseminated tuberculosis. Caseous necrosis on peritoneal histopathology was consistent with patient not being immune suppressed [12].

Full blood count in favour of, not only leukaemoid reaction (Table 1) eluding us, but also peripheral blood changes such as myeloid leukaemia and aplastic anemia have long been described with disseminated tuberculosis [13], and careful haematological study often necessary to exclude TB [14], with miliary TB in compromised host often cryptic and rapidly progressive. A continued abnormal blood picture after initiation of anti-TB treatment necessitates investigation for hematologic malignancy [15]. In our patient the full blood changes came back to normal in two week of anti-TB treatment except next bout of leucocytosis was because of ventilator associated pneumonia. (Blood cultures reports and sensitivity tests in second and third week of admission at secondary hospital in appendix B) Her full blood count remained normal in follow-up after completing the anti-TB regime for 9 months.

\begin{tabular}{|l|l|l|l|l|l|l|l|}
\hline & Before TB & 1st week of Anti-TB & 3rd & 4th & 5th & 6th & 7th Discharge \\
\hline Leukocyte count & $18.3,000$ & 32,450 & 19,000 & $15.2,000$ & 8.200 & & \\
\hline Neutrophils & $74 \%$ & & $87.8 \%$ & & & \\
\hline Lymphocytes & $13 \%$ & & $5.5 \%$ & & & \\
\hline Monocytes & $8 \%$ & & $6.5 \%$ & & & \\
\hline Eosinophil & $5 \%$ & & $0.1 \%$ & & & \\
\hline Basophil & $0 \%$ & $0.1 \%$ & & & \\
\hline $\begin{array}{l}\text { Immature cell } \\
\text { Band form }\end{array}$ & $5 \%$ & nil & & & \\
\hline Metamyelocyte & $1 \%$ & & nil & & & \\
\hline
\end{tabular}

Table 1: Total and differential counts before and after institution of specific anti-TB regime

Finding of abnormal alkaline phosphatase, associated with normal transaminase and bilirubin levels, low albumin, reverse albumin globulin ratio, hypocalcemia in this case was consistent reports by Klaus-Dieter Lessnau [16], Viroj Wiwanitkit et al. [17] and A. Farhadi et al. [18] and Sharma et al. [2]. The high alkaline phosphatase out of proportion to transaminases (Table 2) together with high serum B12 level were a clue of disseminated hepatic involvement [2] in our case. However, Ashish Anantrao Jadhay et al. [19] had reported that higher proportion of pleural to serum alkaline phosphatase is helpful to differentiate tuberculous pleural effusion from non-tuberculous pleural effusion. It was reported in personalized health information in review article [20] that alkaline phosphatase is high in tuberculosis. Therefore, alkaline phosphastase is raided in tuberculosis not necessarily to involve the liver. Further larger studies should be carried out to know the significance of high alkaline phosphatase in tuberculosis to differentiate septicaemia due to $\mathrm{TB}$ from non-TB infections in the settings of primary level hospital where if it presents in unusual presentation like our patient such as negative sputum for AFB and chest X-ray is normal (Table 2). It is also important to carry out further larger studies know the relation of low albumin, low albumin to globulin ratio, high serum B12 level, low serum iron and low total iron capacity (Table 3)with military tuberculosis so that it can make a diagnostic criteria such as Jones' criteria for rheumatic fever and Duke's criteria for infective endocarditis when blood culture is atypical and Echo heart is not typical of vegetation.

\begin{tabular}{|l|l|l|l|l|l|l|l|}
\hline & Before TB & 1st week of Anti-TB & 3rd & 4th & 5th & 6th & 7th \\
\hline Alkaline phosphatase & $509 \mathrm{IU} / \mathrm{L}(40-120)$ & $124 \mathrm{IU} / \mathrm{L}$ & 525 & 343 & 340 & 334 & 321 \\
\hline Aspartate Aminotransferase & $109 \mathrm{IU} / \mathrm{L}(0-40)$ & $1595 \mathrm{IU} / \mathrm{L}$ & 106 & 36 & 34 & 34 & 35 \\
\hline
\end{tabular}




\begin{tabular}{|l|l|l|l|l|l|l|l|}
\hline & & (Drug induced hepatitis) & & & & & \\
\hline Alanine Aminotransferase & $60 \mathrm{IU} / \mathrm{L}(0-40)$ & $1044 \mathrm{IU} / \mathrm{L}$ & 111 & 33 & 30 & 32 & 34 \\
\hline Total protein & $90 \mathrm{G} / \mathrm{L}(60-80)$ & 55 & 53 & 49 & & & 61 \\
\hline Albumin & $18 \mathrm{G} / \mathrm{L}(40-60)$ & 19 & 20 & 20 & & & 28 \\
\hline Globulin & $72 \mathrm{G} / \mathrm{L}(20-40)$ & 36 & 33 & 29 & & & 23 \\
\hline A/G ratio & $<1$ & $<1$ & $<1$ & $<1$ & & & $>1$ \\
\hline Bilirubin & $9 \mu \mathrm{mol} / \mathrm{L}<17 \mathrm{mmol} / \mathrm{L}$ & $16 \mathrm{mmol} / \mathrm{L}$ & & 6.1 & & & 5 \\
\hline
\end{tabular}

Table 2: Liver function tests before and after institution of specific anti-TB regime

\section{Learning Facts by Case Study}

Anti-TB treatment should be strongly considered in any patient with prolonged fever or pyrexia of unknown origin especially in endemic regions and susceptible individual.

By the fact that even among experienced radiologists the sensitivity of chest X-ray in identifying miliary TB is not that yielding, so much that high index of suspicion and clinical judgement is key for both making a diagnosis and successfully treating pediatric TB.

Timely institution of anti-TB drugs after first admission would have likely contained the infection, avoided tuberculous meningitis and the high cost of prolonged ICU admission. In this case, a thoracic CT scan following a negative chest X-ray should have been done where pulmonary tuberculosis was a possibility. The high alkaline phosphatase out of proportion to transaminases together with high serum B12 level were a clue of disseminated hepatic involvement [2], and a liver biopsy may have established the diagnosis and avoided the mini-laparotomy. Ashish Anantrao Jadhay et al. [19] had reported that higher proportion of pleural to serum alkaline phosphatase is helpful to differentiate tuberculous pleural effusion from non-tuberculous pleural effusion. It was reported in personlaized health information in review article [20] that alkaline phosphatase is high in tuberculosis [21]. Therefore, alkaline phosphastase is raided in tuberculosis not necessarily to involve the liver. Further larger studies should be carried out to know the significance of high alkaline phosphatase in tuberculosis to differentiate septicaemia due to TB from non-TB infections in the settings of primary level hospital where if it presents in unusual presentation like our patient such as negative sputum for $\mathrm{AFB}$ and chest X-ray is normal (Table 2). It is also important to carry out further larger studies know the relation of low albumin, low albumin to globulin ratio, high serum B12 level, low serum iron and low total iron capacity (Table 3)with military tuberculosis so that it can make a diagnostic criteria such as Jones' criteria for rheumatic fever and Duke's criteria for infective endocarditis when blood culture is atypical and Echo heart is not typical of vegetation.

\begin{tabular}{|l|l|}
\hline $\mathrm{Hb}$ & $8.8 \mathrm{G} / \mathrm{L}$ \\
\hline Platelet count & $494,000 / \mathrm{dl}$ \\
\hline ESR & $180 \mathrm{~mm} / 1 \mathrm{sthr}$ \\
\hline Chest X-ray & Normal \\
\hline Monteux test & Negative \\
\hline Blood culture & negative \\
\hline
\end{tabular}

\begin{tabular}{|l|l|}
\hline Blood for malaria parasite & negative \\
\hline Urine FEME & Leu 25/HPF and protein $1+$ \\
\hline Leptospirosis antibody & negative \\
\hline Serology for Meloidosis & negative \\
\hline HIV antibody & negative \\
\hline Hepatitis B serology & negative \\
\hline Hepatitis C serology & negative \\
\hline Serum B12 & $781 \mathrm{pmol} / \mathrm{L}(156-698)$ \\
\hline Serum folate & $10.7 \mathrm{nmol} / \mathrm{L}(7-39.7)$ \\
\hline Serum Iron & $7 \mu \mathrm{mol} / \mathrm{L}(6.6-26)$ \\
\hline Serum Ferritin & $291.3 \mathrm{ug} / \mathrm{L}(13-150)$ \\
\hline Seurm total iron binding capacity & $33 \mu \mathrm{mol} / \mathrm{L}(40.8-76.6)$ \\
\hline Serum unbound iron & $26 \mu \mathrm{mol} / \mathrm{L} \mathrm{(19.7-66.2)}$ \\
\hline Serum calcium & $1.84 \mathrm{mmol} / \mathrm{L}(2.09-2.54)$ \\
\hline
\end{tabular}

Table 3: Other parameters of investigations in the initial hospital

\section{Conclusion}

Disseminated tuberculosis is often fatal if therapy is delayed, and anti-TB regime initiated a month following admission improved the patient and corrected the hematologic picture and improve the level of alkaline phosphatase within two weeks.

Patients with pyrexia of unknown origin with cough with and biochemical features of septicemia and non-specific hetatitis features or elevated alkaline phosphatase with normal transaminases with no growth in blood culture and absence of features of other infiltrative lesions, it is worth to start the anti-TB drugs in susceptible persons and endemic areas of tuberculosis although sputum for AFB is negative and chest X-ray is normal.

\section{Acknowledgments}

We are thankful to hospital director of secondary hospital to study the case note and mother of the patient to allow using the CT images for continuous medical education. 
Citation: Aye M, Cabot JSF, Baba S, Thanabalan MC, Chung SF (2014) Disseminated Tuberculosis - A Case Study. J Metabolic Synd 3: 1000140. doi:10.4172/2167-0943.1000140

Page 4 of 4

\section{References}

1. Manget JJ. SepulchreTumseanatomicapractica. Voll. Observatio XLVII, Cramer and Perachon, London.

2. Sharma SK, Mohan A, Sharma A (2012) Challenges in the diagnosis \& treatment of miliary tuberculosis. Indian J Med Res 135: 703-730.

3. Alvarez S, McCabe WR (1984) Extrapulmonary tuberculosis revisited: a review of experience at Boston City and other hospitals. Medicine (Baltimore) 63: 25-55.

4. Gurkan F, Bosnak M, Dikici B, Bosnak V, Yaramis A, et al. (1998) Miliary tuberculosis in children: a clinical review. Scand J Infect Dis 30: 359-362.

5. Hussey G, Chisholm T, Kibel M (1991) Miliary tuberculosis in children: a review of 94 cases. Pediatr Infect Dis J 10: 832-836.

6. Kim PK, Lee JS, Yun DJ (1969) Clinical review of miliary tuberculosis in Korean children. 84 cases and review of the literature. Yonsei Med J 10: 146-152.

7. Long R, O'Connor R, Palayew M, Hershfield E, Manfreda J (1997) Disseminated tuberculosis with and without a miliary pattern on chest radiograph: a clinical-pathologic-radiologic correlation. Int J Tuberc Lung Dis 1: 52-58.

8. Alsoub H, Al Alousi FS (2001) Miliary tuberculosis in Qatar: a review of 32 adult cases. Ann Saudi Med 21: 16-20.

9. Somu N, Vijayasekaran D, Ravikumar T, Balachandran A, Subramanyam L, et al. (1994) Tuberculous disease in a pediatric referral centre: 16 years' experience. Indian Pediatr 31: 1245-1249.

10. Udani PM, Bhat US, Bhave SK, Ezuthachan SG, Shetty VV (1976) Problem of tuberculosis in children in India epidemiology, morbidity, mortality and control programme. Indian Pediatr 13: 881-890.
11. Miliary Tuberculosis. thelungcenter.co.in

12. SC Andres.A Case Series on Disseminated Tuberculosis

13. Mert A, Ozaras R (2005) A terminological controversy: do disseminated and miliary tuberculosis mean the same? Respiration 72: 113.

14. Hughes JT, Johnstone RM, Scott AC, Stewart PD (1959) Leukaemoid reactions in disseminated tuberculosis. J ClinPathol 12: 307-311.

15. Sinha S, Basil K, Sanyal S (1991) Myeloid leukemoid reactions in cases of disseminated tuberculosis andtuberculous meningitis. Ind J Tub38:159

16. Uetake T, Sakamaki T, Onozawa Y, Kimura H, Fukayama M (1990) [Clinicopathological study of miliary tuberculosis in patients with hematologic disease]. Kekkaku 65: 273-283.

17. Klaus-Dieter Lessnau.Miliary Tuberculosis Updated: Sep 13, 2013

18. Wiwanitkit V (2001) High serum alkaline phosphatase levels, a study in 181 Thai adult hospitalized patients. BMC FamPract 2: 2 .

19. Farhadi A, Parhizager, Rahman S (1999) Tuberculosis:The most common cause of fever of undetermined origin in Shiraz. Original article. Archives of Iranian Medicine.

20. Jadhav AA, Bardapurkar JS, Jain A (2009) Alkaline phosphatase: Distinguishing between tuberculous and nontuberculous pleural effusion. Lung India 26: 77-80.

21. Health me. Review: Could TB cause elevation of alkaline phosphatase? Personalized health information. 